\title{
USING UAV TO DETECT SHORELINE CHANGES: CASE STUDY - POHRANOV POND, CZECH REPUBLIC
}

\author{
I. Čermákováa ${ }^{a}$, J. Komárková a ${ }^{a}$ P. Sedlák ${ }^{\text {a, * }}$ \\ ${ }^{a}$ University of Pardubice, Faculty of Economics and Administration, 53210 Studentská 95 Pardubice, Czech Republic - \\ st32689@student.upce.cz, (jitka.komarkova, pavel.sedlak)@upce.cz
}

\section{Commission ICWG I/Vb}

KEY WORDS: Landscape, Pohranov pond, landscape indices, UAV, change the landscape

\begin{abstract}
:
The paper describes utilization of an unmanned aerial vehicle (UAV) for detection of changes of shorelines. UAV is used as a cheep and ondemand available possibility how to collect remotely sensed data. Its utilization is limited by legal regulations and weather conditions. Paper deals with utilization of UAV for monitoring small water area and particularly study of changes of shorelines. Study contains other methods of classification. After classification will be data processed for next calculations. Indices regarding shoreline changes are in the study also. In conclusion, study contains obtainment findings and encouragement for the future.
\end{abstract}

\section{INTRODUCTION}

Studying changes of landscape is a very important issue in the modern society. It means that the society is interested in new findings which can help to understand how nature and its particular elements exist and behave. Understanding functions, relationships and rules can support landscape management and further sustainable development e.g. prevention of devastating impacts of floods. Monitoring of drought (which was the key problem of this summer season) is another example. Thus, many studies (e.g. Bortoleto et al., 2016; Qindong and Shengyan, 2016; Kotzee and Reyers, 2016; Dobešová et al. 2014) are focused on landscape changes. Some studies are particularly focused on water bodies (e.g. Gallop et al., 2015; Pechanec et al., 2015; Heine et al., 2015).

Remote sensing is very often used as a source of data for observation of landscape and terrain. There are many issues why this method is more reasonable than in situ observations, sampling and measurements and land surveying. It means the costs are lower (namely in case when bigger areas are monitored), accuracy and spatial resolution is adequate to aims of studies and finally data measured in various parts of electromagnetic spectrum are available. The last advantage is important for researches based on thermal imagery, various indices, etc. Satellites or aerial imagery is available for monitoring larger areas. Unmanned aerial vehicles (UAV) are increasingly used to monitor small areas, e.g. small water bodies (ponds). UAVs can provide results faster and usually with higher spatial resolution.

Aim of the study is to extend research of the Faculty of Chemical Technology of University of Pardubice. This research is focused on using remote sensing for studying chemical processes and composition of various types of soils, e.g. of water sediments. Main part of this case study is a study of small water bodies which are monitored by an UAV. At first, a suitable way of utilization of an UAV for data collection is proposed. Next, collected data are processed to calculate shoreline changes. Only a part of the shoreline of a pound is used to demonstrate the proposed procedure within the case study.

\section{PREVIOUS RESEARCHES}

Detection of landscape changes is a very important part of landscape management. Remote sensing (including UAVs) is used to collect up-to-date data in various parts of electromagnetic spectrum. Data are processed by many different methods according to their content and expected results (e.g. Heine, 2015; Li et al., 2013; Nath and Deb, 2010).

\subsection{Landscape changes}

Many researches focused on landscape changes have been published. Qindong and Shengyan (2016) analyzed landscape pattern changes in monitored period (1990 - 2013) and identified driving sources during that period. They used various landscape indices to calculate landscape changes.

Bortoleto et al. (2016) focused on index of restoration in landscapes. They proposed a mathematical index named SIR that describes suitability of individual habitat patches for restoration within a landscape. A model based on the SIR used a map of distance classes among fragments and a map of habitat quality established according to each land cover category. SIR was obtained as a result of calculation.

\subsection{Water bodies and shoreline changes}

Kotzee and Reyers (2016) dealt with floods in South Africa. Study was focused on analyses of three municipalities affected by a flood in the monitored area (South Africa). Principal component analysis was used to explore level of disaster planning, mitigation and next potential occurrences or increased number of occurrences of floods. 
Many articles were particularly focused on various water bodies and their shorelines. Gallop et al. (2015) studied longterm changes of shoreline in southwestern Australia. Shoreline changes were observed in the period of 34 years. Aerial photographs were used as a data source. It was realized that over $96 \%$ beaches straightened during the time period. Figure 1 shows digitized vegetation lines and shore lines from 1974 to 2008. Empirical Orthogonal Function (EOF) helped to explain $45 \%$ of variability between transects of beach. In this case, there were large changes in shoreline position that did not correspond to the indices of annual wave conditions. In future, there is big potential for improvement of this research by remote sensing and increased utilization of fuzzy-based computer algorithms.

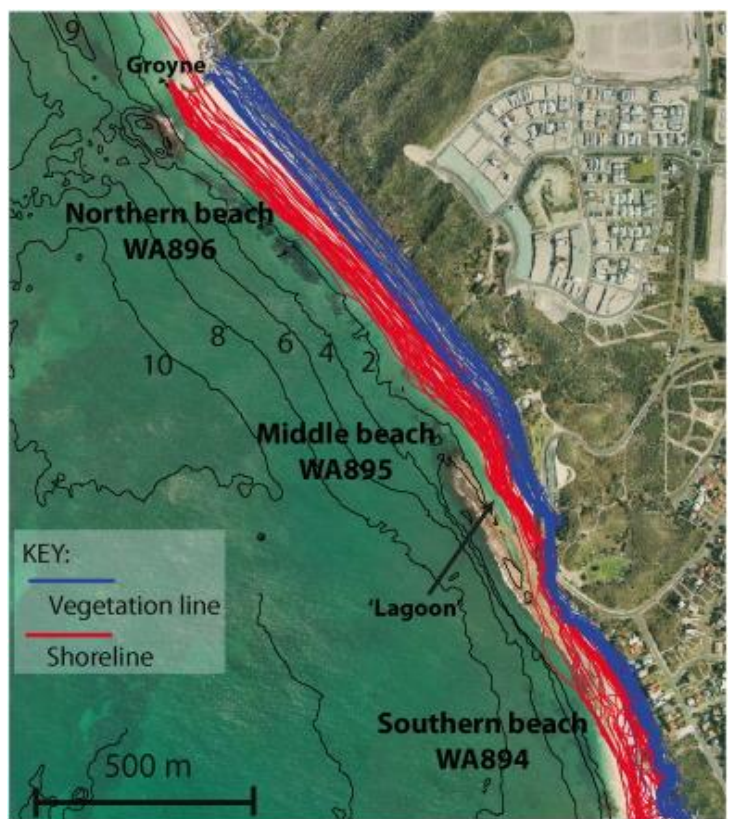

Fig. 1: Vegetation lines and shore lines from 1974 to 2008, source: Gallop et al. (2015)

Studies Misra and Balaji (2015); Adarsa et al. (2015) and Nandi et al. (2015) used Digital Shoreline Analysis System (DSAS) for detection of changes of shoreline in a monitored area. DSAS is a special extension which is focused on shoreline analysis. This software can calculate the rate of shoreline change. Example from this study is available in Figure 2.

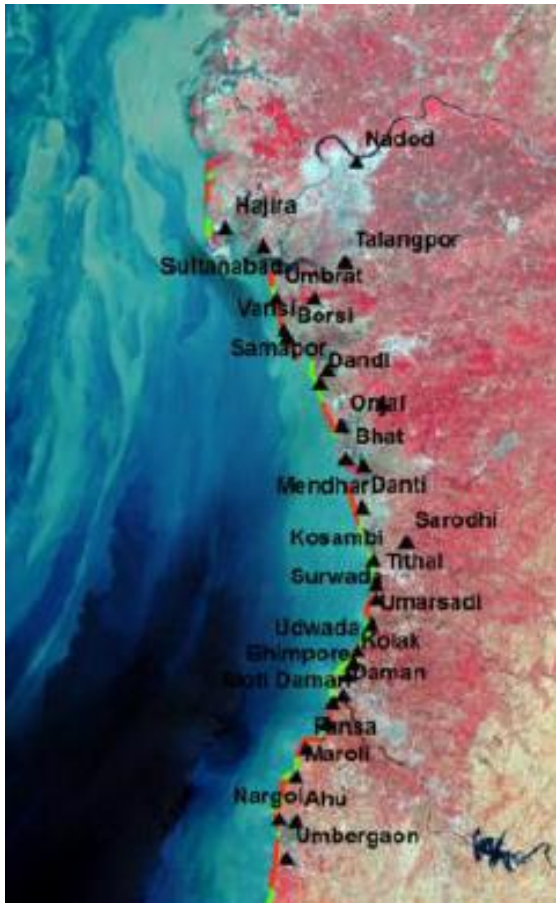

Fig. 1: Shoreline changes between 1990- 2014, analysis provided in DSAS, source: Misra and Balaji (2015)

Water erosion of the river Trkmanka shoreline (a small stream in South Moravia, the Czech Republic) was studied by Pechanec et al. (2015). They focused on erosion susceptibility and shoreline changes because they assumed that water erosion destructively influences the soil surface. This method provides maximum volume of soil erosion caused by water.

Tamborski et al. (2015) monitored Long Island in New York. The research was focused on submarine water discharge. Landsat data (TIR) could not be used because data was unable to resolve anomalies. Thus, thermal infrared images were used instead of TIR data. Data was provided by aerial vehicle and then it was analysed by water temperature. Study of shoreline was done manually, i.e. water was sampled near the beach and samples were analysed in a laboratory.

In the study of Pacheco et al. (2015), bathymetry for shallow water was primary proposed to monitor both beach and shoreface. LIDAR data (Light Detection and Ranging) were used. Depth-retrieval algorithm was proposed to process data including bathymetry based on LIDAR data.

Several studies were directly focused on small water bodies, e.g. Heine et al. (2015), Zlinsky et al. (2011) and Works Jr and Gilmer (1976).

Normalized Difference Water Index (NDWI) was proposed by McFeeters (1996) to delineate open water features and enhance their presence in remotely-sensed digital imagery. The NDWI uses reflected near-infrared radiation and visible green light to enhance the presence of water bodies and to eliminate the presence of soil and terrestrial vegetation features. 


\subsection{Unmanned aerial vehicle}

Fahlstrom and Gleason (2012) classified aircrafts that fly without pilots into three basic types. They are: UAV, remotely piloted vehicles (RPVs) and drones, respectively. All are unmanned so the name "unmanned aerial vehicle" or an UAV can be thought of as the most general term. Some people use terms RPV and UAV interchangeably. But, the remotely piloted vehicle is fully piloted or controlled from a remotely located position. On the other side, UAV may perform autonomous or pre-programmed missions. So, an RPV is always an UAV but an UAV need not always be an RPV.

Rathinam S. et al. (2007) used an UAV to detect and track a river by means of visible and near infra-red sensor

Shorelines can be used to autonomously navigate UAVs as proposed by Baker (2010). A near-infrared sensor allows the vision system to distinguish water from land. The vision system then issues commands to the autopilot to follow the coastline or the riverbank.

\section{CASE STUDY}

The case study is focused on utilization of an UAV for monitoring of a small water area. The particular aim is to delineate a part of a shoreline of the chosen pond. Because of UAV utilization, there is no multi-spectral data available, so many indices used to detect landscape changes cannot be used. UAV is equipped with a common DJI video camera because no professional camera was available. A fast and cheap data collection with a commonly available equipment is the main objective of this research. NDWI cannot be used as well. This is the reason why landscape indices are used in the case study.

\subsection{Area of Interest}

Area of interest is located close to the city of Pardubice, in the Czech Republic. The case study studies part of a shoreline of the Pohranov pond, close to the municipality of Pohranov (see Figure 3.). Size of the pond is $0.4 \mathrm{~km}^{2}$ (Pardubický kraj, 2015).

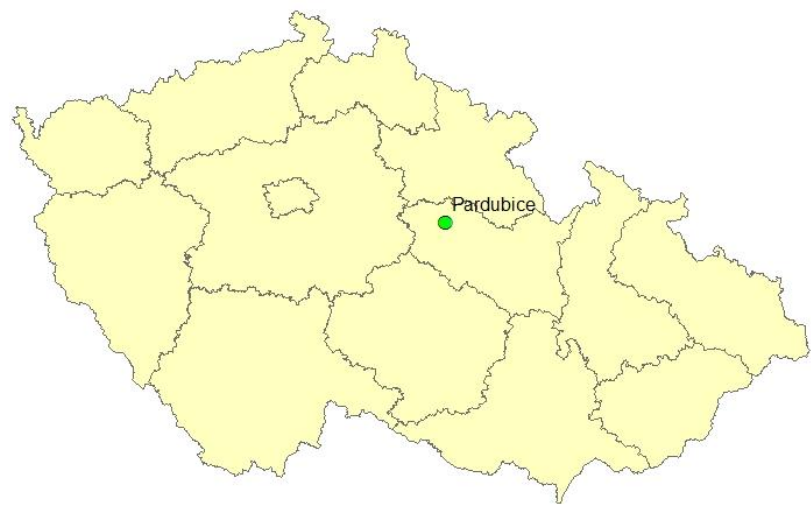

Fig. 3: Placement of the city of Pardubice in the Czech Republic, source: authors

\subsection{Data collection}

The pond is surrounded by forest. It means that in situ observation is difficult. Satellite imaginary does not provide data with a suitable resolution. UAV represents a more suitable way of data collection in this case.

UAV provides data in necessary high distinction and costs are also lower. Tarot 690 is used for monitoring pond Pohranov. It can be characterised as follows: airscrew gear; 6 gears; 0.985 $\mathrm{m}$ average of impeller; $0.35 \mathrm{~m}$ height, $70 \mathrm{~km} / \mathrm{h}$ maximum speed. This UAV has the following restrictions (conditions under which it cannot be used): temperature under $-10{ }^{\circ} \mathrm{C}$; wind fasters than $10 \mathrm{~m} . \mathrm{s}^{-1}$; fog with visibility under $100 \mathrm{~m}$; creation frost on the airscrew; drizzle, rain and snowfall. Figure 4 shows the UAV used for monitoring Pohranov pond.

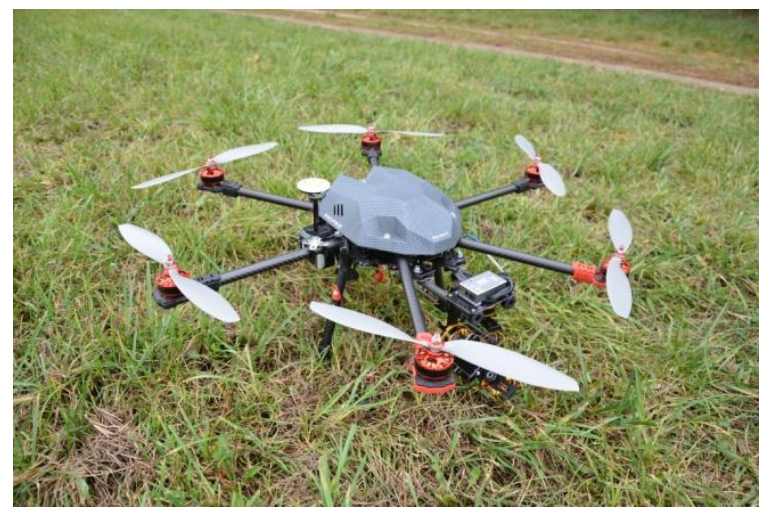

Fig. 4: UAV used for monitoring pond Pohranov, source: authors

Measurements must be done several times in different days to obtain a short time series. Time horizons were selected according to the above listed weather conditions and to cover a longer time period, namely: 7. 7. 2015, 18. 7. 2015, 23. 8 . 2015 and 2. 11. 2015. Height of flight is $80 \mathrm{~m}$ (the height was set up in the software of UAV before flight) for all flights.

\subsection{Data processing and visualization}

Video collected by the UAV camera is in the visible part of the spectrum only.

Video provided from UAV must be at first processed to create one image from each observation. Primarily, images must be selected and created from the video. Freely available software Free Video to JPG Converter is used for this step. Merging all collected images into one picture is the next step. Image Composite Editor (freely available) is used for this step. A mosaic created from images is minimally distorted because only central parts are selected for merging. The central parts of images are insusceptible to distortion. The resulted images represent our monitored area and changes during monitoring time period. Georeferencing is the next step. Orthophoto data set coming from State Administration of Land Surveying and Cadastre (ĆUZK) is used as a reference data set. The data set is available in geoportal and it is distributed by web map service (WMS). ArcGIS for Desktop (version 10.2) is used for georeferencing because it supports both the required function and WMS services. Georeferencing with RMS $=0.012103$ is considered as successful.

Shorelines definition is the following step of all images processing. ArcGIS for Desktop is again used. The polylines 
are manually created in a form of new shapefiles (see Figure $5)$.

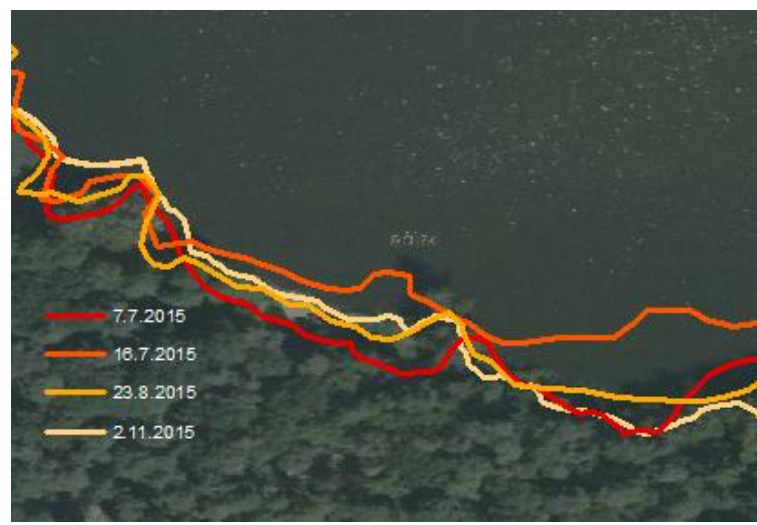

Fig. 5: Define shorelines for every monitoring, source: authors

Extension of ArcGIS for Desktop - Image Analysis, is used for studying shoreline, and particularly their changes. This extension is used as a tool for supervised and unsupervised classification also. Supervised classification (Seed tool) and next creating polyline is available (see Figure 6). Unsupervised classification is available in the way shown by Figure 7. An approximate scale of figures 5,6 and 7 is $1: 785$ 000000 . Next, resulting polygons are converted into polylines. Polylines must be repaired in both cases because shadows are visible in the images. Irregular texture is visible in both images. It decreases quality of classifications. In this case images must be repaired by observer. So, polylines created by observer are used for the following calculation of indices (Figure 5).

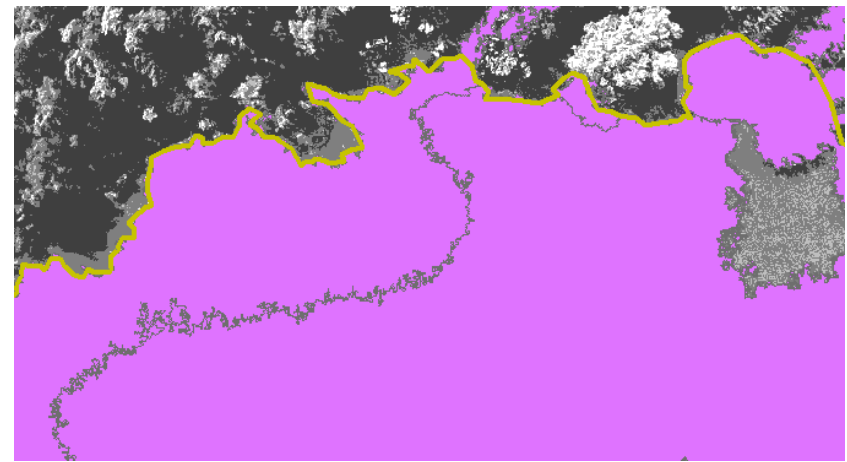

Fig. 6: Supervised classification in 7.7.2015, source: authors

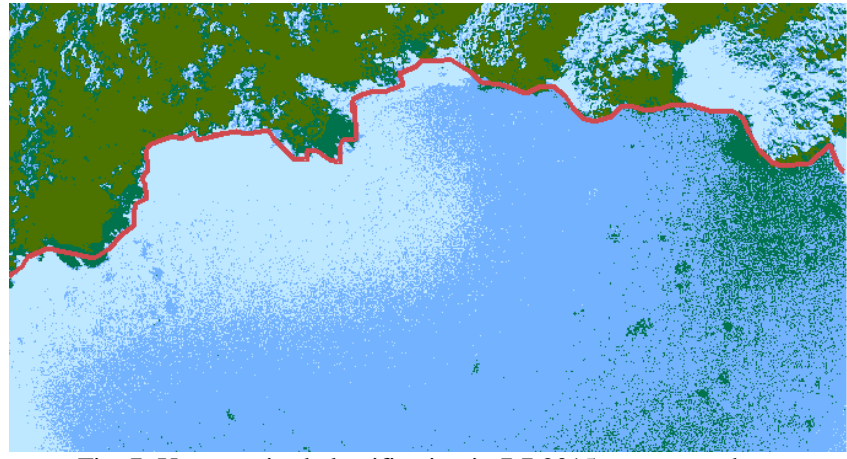

Fig. 7: Unsupervised classification in 7.7.2015, source: authors
Only three observations are used for indices calculation, because during the last observation the pond was drain (fish out) and it is a long time from the previous observation. Drain pond is available in Figure 8.

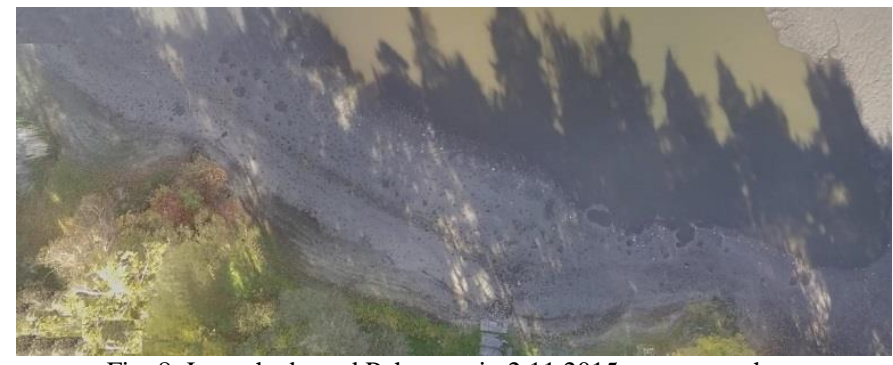

Fig. 8: Launched pond Pohranov in 2.11.2015, source: authors

Firstly, changes of size of shorelines in monitored time period are calculated. In the Table 1 , there are visible changes in metres (Shape_change) and percentage (Shape_change_\%) in monitored time period. The values regarding length are extracted from the software, values regarding change are calculated by authors.

Table 1: Shoreline changes in metres and percentage, source: authors

\begin{tabular}{|r|l|r|r|r|r|}
\hline OBJECTID & Shape & DATE & Shape_Lenght & Shape_change & Shape_change_\% \\
\hline 1 & Polyline & 7.7 .2015 & 274.254 & & \\
\hline 2 & Polyline & 16.7 .2015 & 241.546 & 32.708 & 11.926 \\
\hline 3 & Polyline & 23.8 .2015 & 255.510 & 18.744 & 6.835 \\
\hline
\end{tabular}

Various indices can be used for calculation of shoreline changes. Because only data in the visible part of spectrum is available, only the most often used landscape indices are used in the case study.

The simplest index regarding changes in the landscape is Coefficient of the Ecologic Stability $\left(\mathrm{K}_{\mathrm{es}}\right)$ by Černohouz (2011). $\mathrm{K}_{\mathrm{es}}$ calculates changes by data (areas) dividing on relatively stability and relatively instability:

$$
\mathrm{K}_{\mathrm{es}}=\frac{S}{L}
$$

where $\mathrm{S}=$ area of relatively stability (in metres), $\mathrm{L}=$ area of relatively instability (in metres).

Resulting coefficient value is between zero and infinity. Nearly to zero value means that the area is ecological unstable, value higher more than three means ecological stability which do not need intervention of human beings.

It is necessary to choose stability observation before calculation. First observation is chosen as a stabile one. After calculation it is found that both observations are stable. 16. 7. 2015 is $\mathrm{K}_{\mathrm{es}} 7.38$ and 23. 8. 2015 is $\mathrm{K}_{\mathrm{es}} 13.63$. It means that the area in the drought state is still stabile but there is a big fluctuation. So it is going to be monitored in next years.

Černohouz (2011) also used index $\mathrm{K}_{\mathrm{es}}$ modified by Agroproject. This index is calculated in percentage.

$$
\mathrm{K}_{\mathrm{es}}=\frac{1.5 * A+B+0.5 * C}{0.2 * D+0.8 * E}
$$


$\mathrm{A}=$ percentage of area with the 5 th level of quality (the best, stable system)

$\mathrm{B}=$ percentage of area with the 4th level of quality

$\mathrm{C}=$ percentage of area with the 3 rd level of quality

$\mathrm{D}=$ percentage of area with the 2 nd level of quality

$\mathrm{E}=$ percentage of area with the 1st level of quality (the worst, unstable system)

In the case that the coefficient is one or lower, the landscape is unstable, otherwise it is stable. For this calculation, the formula is simplified. Formula contains only stable area and unstable area, because the research is focused on shorelines and their changes only. It is found by the modified coefficient that in both time periods (the first observation is chosen as a stable one) is shoreline stable. Modified $\mathrm{K}_{\mathrm{es}}$ is equal to 13.85 on 16. 7. 2015 and to 25.56 on 23. 8. 2015.

According to Guth and Kučera (1997), Index of Diversity is used for detection of landscape changes too. The index informs about heterogeneity of landscape structures. Formula is as follows:

$$
\begin{aligned}
& H=-\operatorname{sum}\left(A_{i} \log A_{i}\right) \\
& A_{i}=\text { relative area covers } i \text {-class of covers for } n \text { classes }
\end{aligned}
$$

First observation is chosen as the stable one again. Then, data is divided into two classes. The first class is stable and the second class is unstable. In the case of this formula, it is necessary to recalculate data to percentage. Diversity in the second observation is 0.15 and in the third observation 0.11 . This is a low value. It means that the land cover is more homogeneous (stable in this case). For the next index it is necessary to count Maximum Diversity:

$$
\begin{aligned}
& \mathrm{H}_{\max }=\log (\mathrm{n}) \\
& \mathrm{n}=\text { count of classes }
\end{aligned}
$$

Calculation of the Index of Dominancy is the next step. This index represents relative substitution of single classes. Index of dominancy is counted by the following way:

$$
\mathrm{D}=\mathrm{H}_{\max }-\mathrm{H}
$$

For the second observation time, D is 0.54 and for the third observation time it is 0.59 . These are higher numbers than it is obvious. Obvious are numbers near to zero which mean that in the landscape there are not dominant only several covers. In this case it means that landscape changes are stable in the monitored time period.

According to the calculated indices it can be concluded that shoreline changes in the monitored time period was not larger than it was expected. But there are some fluctuations which require more observations of the monitored area in the future.

\section{CONCLUSION}

Utilization of UAVs for landscape and water monitoring is rapidly increasing. UAVs represent one of several available methods how to observe changes of landscape. Importance of this method increases because there are many different possibilities of utilization of data collected by UAVs. The next important issue is availability of measurements - utilization of UAVs is limited by weather conditions only.

The research aims to extend research of the Faculty of Chemical Technology in the future (sampling and consequent chemical analyses of water samples to detect water quality and pollution). The main objective of this paper is to propose a suitable way of utilization of UAVs for detection of changes of small water bodies' shorelines. Proposed procedure is applied to the Pohranov pond in Pardubice Region. The main output of the case study is the proposed procedure. The research can be extended to whole Pohranov pond and fully generalized in the future. Utilization of different sensors connected to an UAV can allow identification of water pollution and cooperation with the Faculty of Chemical Technology can allow verification of obtained results at first. As a final result, faster and cheaper way of pollution identification by UAVs will be proposed.

\section{ACKNOWLEDGMENTS}

The paper has been completed with the kind support of SGS project of Faculty of Economics and Administration, University of Pardubice.

\section{REFERENCES}

Adarsa J. et al., 2012. Morphological Change Study of Ghoramara Island, Eastern India Using Multi Temporal Satellite Data. Research Journal of Recent Sciences 1(10), pp. 72-81

Baker P. et al. 2010. Using shorelines for autonomous air vehicle guidance. Computer Vision and Image Understanding 114 (2010), pp. 723-729

Bortoleto L. A., 2016. Suitability index for restoration in landscapes: An alternative proposal for restoration projects. Ecological Indicators 1(2016), pp. 724-735

Černohouz, O. Analýza změny využití krajiny v katastru Růžová. Ústí nad Labem, 2011. Master thesis. University of J. E. Purkyně.

Dobešová Z. et al., 2014. International neural networks and GIS in modeling landscape changes. In: International Multidisciplinary Scientific GeoConference Surveying Geology and Mining Ecology Management 1(2014), pp. 651-658

Fahlstrom, P. G. and Gleason, T. J.. Introduction to UAV systems. 4th ed. Chichester: John Wiley \& Sons, 2012, xxv, 280 s. Aerospace series. ISBN 978-1-119-97866-4.

Gallop, S. L., et al., 2015. The impact of temperate reefs on 34 years of shoreline and vegetation line stability at Yanchep, southwestern Australia and implications for coastal setback. Marine Geology 369(2015), pp. 224-232.

Geoportál ČÚZK: př́stup k mapovým produktům a službám resortu Prague: ČÚZK, 2010 [access date: 2015-11-19]. available online: http://geoportal.cuzk.cz/

Guth J. and Kučera T., 1997. Monitoring of Land Cover Change with Using the Remote Sensing and GIS. Př́roda 10(1997), pp. 107-124

Heine I. et al., 2015. Reconstruction of Lake Level Changes of Groundwater Fed Lakes in Northeastern Germany Using RapidEye Time Series. Water 7(2015), pp. 4175-4199 
Li W. et al., 2013. A Comparison of Land Surface Water Mapping Using the Normalized Difference Water Index from TM, ETM+ and ALI. Remote Sensing 5(2013), pp.5530-5549

Kotzee I. and Reyers B., 2016. Piloting a social-ecological index for measuring flood resilience: A composite index approach. Ecological Indicators 2(2016), pp. 45-53

McFeeters S. K., 1996. The use of the Normalized Difference Water Index (NDWI) in the delineation of open water features. International Journal of Remote Sensing 17(7), pp. 1425-1432.

Misra A. and Balaji R., 2015. A Study on the Shoreline Changes and LANDuse/ Land-cover along the South Gujarat Coastline. Procedia Engineering 6(116), pp. 381-389

Nandi S. et al., 2015. Shoreline shifting and its prediction using remote sensing and GIS techniques: a case study of Sagar Island, West Bengal (India). Journal of Coastal Conservation 10(2015), pp. 1-20

Nath R. K., Deb S. K., 2010. Water-Body Area Extraction from High Resolution Satellite Images-An Introduction, Review, and Comparison. International Journal of Image Processing 6(3), pp. 353 -372

Pacheco A., et al., 2015. Retrieval of nearshore bathymetry from Landsat 8 images: A tool for coastal monitoring in shallow waters. Remote Sensing of Enviroment 46(159), pp. 102-116

Pardubický kraj: Region budoucnosti 2014/2015. Pardubice, 2015 [access date: 2015-11-24]. available online: www.pardubickykraj.cz
Pechanec, V. et al., 2015. Decision support tool for the evaluation of landscapes. Ecological Informatics s. 4 available online: http://rj7gv6cf9w.search.serialssolutions.com//?sid=Elsevier:Scopus\&genre= nknown \&issn $=15749541 \&$ volume $=\&$ issue $=\&$ spage $=\&$ epage $=\&$ pages $=\&$ artn um $=\&$ date $=2014 \&$ title $=$ Ecological + Informatics \&atitle $=$ Decision+support+too $1+$ for+the+evaluation+of+landscapes\&aufirst $=V$.\&auinit=V.\&auinit $1=V \&$ aul ast $=$ Pechanec $\& i d=$ doi:10.1016\%2fj.ecoinf .2015 .06 .006

Qindong, F. and Shengyan, D., 2016. Landscape pattern changes at a county scale: A case study in Fengqiu, Henan Province, China from 1990 to 2013. Catena 2(2016), pp.152-160

Rathinam S. et al., 2007. Autonomous Searching and Tracking of a River using an UAV. In: Proceedings of the 2007 American Control Conference, New York City, USA, July 11-13, 2007, pp. 359-364.

Tamborski, J.J., et al., 2015. Identification and quantification of diffuse fresh submarine groundwater discharge via airborne thermal infrared remote sensing. Remote Sensing of Enviroment 46(171): pp. 202-217

Work Jr E.A., Gilmer D.S., 1976. Utilization of Satellite Data for Invent Orying Prairie Ponds and Lakes. Photogrammetric Engineering and Remote Sensing 42(5), pp. 685-694

Zlinszky A. et al., 2011. Initial Report of the Aimwetlab Project:

Simultaneous Airborne Hyperspectral, LIDAR and Photogrammetric Survey of the Full Shoreline of Lake Balaton, Hungary. Geographia Technica 1(2011), pp. 101-117 